\title{
VARIABLES XEOGRÁFICAS E VARIACIÓNS LINGÜÍSTICAS
}

\author{
Augusto Pérez. Alberti \\ Universidade de Santiago de Compostela
}

Non sei ata que punto os lingüistas se pararon a matinar no papel que as variables xeográficas de Galicia teñen na diferenciación lingüística existente. Non sei se tiveron en conta que o noso territorio non é en absoluto uniforme e que contén no seu interior, malia a súa cativa extensión, importantes contrastes xeomorfolóxicos, climáticos, bioxeográficos, etnográficos, sociolóxicos ou económicos, o que ten que materializarse necesariamente en diferenzas na fala.

Por iso, dende a miña moi escasa formación filolóxica, quixera achegar algunhas ideas por se foran de interese para os investigadores, aínda que son consciente de que para os entendidos posiblemente o que vou presentar non teña demasiado valor.

\section{OS CONTRASTES XEOMORFOLÓXICOS}

Hai dous aspectos que definen con claridade o relevo de Galicia: unha gradación de formas dende a costa cara ao interior e a existencia dunha evidente dicotomía horizontalidade/verticalidade en todo o seu territorio. O relevo de Galicia é un auténtico mosaico de pezas fundidas e erguidas que se encadean entre a costa e os límites con Asturias, León, Zamora e Portugal. A medida que nos introducimos cara ao interior, o contraste altitudinal óllase con claridade. Os chanzos achairados son unha constante na fachada occidental mentres que, dende as serras occidentais ata as orientais, o relevo se descompón nun amplo rosario de foxas fundidas e ergueitas.

R. Álvarez, F. Dubert, X. Sousa (eds.): Lingua e Territorio Santiago de Compostela: ILG/CCG, 2006, 175-189 ISBN 84-96530-20-5 
Polo norte, preto do mar, érguense as serras setentrionais que superan no Xistral, os 1.000 metros; polo sur, atopamos as meridionais que acadan os 1500 metros ou as sudorientais que, en Pena Trevinca, superan os 2.000 metros, mentres que polo leste se encadean as orientais, que se aproximan aos 2.000 metros na Serra dos Ancares. E o sector central de Galicia caracterízase, á súa vez, por un amplo conxunto de chairas e foxas tectónicas, coma as da Terra Chá, Lemos, Maceda, A Limia ou Monterrei.

Se analizamos, pois, calquera sector do noso territorio podemos comprobar fortes rupturas de pendente no enlace entre os diferentes niveis achairados e, sobre todo, en certas áreas nas que a incisión fluvial ten sido máis intensa, como é o caso de moitos sectores percorridos polos ríos Sil e Miño, que rachan bruscamente o deseño horizontal das terras de Chantada ou Lemos e xeran impresionantes canóns. Incluso a carón da costa podemos ollar como o Ulla, o Tambre, o Eume, o Sor ou o Eo amosan profundos encaixamentos ata as proximidades da súa desembocadura.

Nun relevo achairado dificilmente atoparemos nomes como $a b a$, abeiro, fraga ou fragoso, máis comúns naqueles lugares de relevo abrupto ou escarpado. Pola contra, o nome de chaira está sempre asociado a un relevo plano e tanto o podemos atopar nas foxas como nas serras. Persoalmente, a primeira ocasión que escoitei falar de chaira a alguén foi en Chaguazoso, para referirse ás turbeiras existentes ao oeste da aldea, hoxe, por certo, desgraciadamente desaparecidas.

Outeiro está asociado a un relevo movido, mentres que corga a un onde o río se encaixa, e veiga alí onde o río xera unha terraza. Beiramar, ribeira, ría, esteiro, punta, angüeiro, con, illa, insua, arnela, estoa, peirao-neste caso, chaira mariña cuberta de bloques e non lugar de amarre-, loxicamente, aparecen na costa. Como en lugares moi concretos da costa, neste caso entre Cabo Silleiro e A Guarda, atopamos o nome de porto reservado a entrantes no litoral por mor da fracturación da rocha tampouco como lugares de amarre.

E se ampliamos a escala de análise e nos centramos nos diferentes tipos de rochas, teremos que recoñecer que certos nomes están vinculados ás rochas graníticas, caso de moa ou castelo, incluso penedos, aínda que estes tamén poden aparecer noutros tipos de rocha. Pola contra, louseiras, lousado e outros nomes que non coñezo, mais que ben seguro 
que existen, están en relación coa presenza de rochas metamórficas como os xistos, as cuarcitas ou as lousas.

Por outra parte, non podemos deixar á beira o feito de que en función da configuración do relevo e da súa evolución podemos atopar potentes formacións superficiais ás que se dan nomes como pedrido, pedreira ou pedregal, que aparecen unicamente alí onde existe unha potente cobertura sedimentaria, na meirande parte asociada a procesos de orixe fría que en Galicia se deron hai uns trinta ou corenta mil anos. Os potentes mantos de bloques que aparecen en diferentes lugares da costa darán orixe ao nome de coídos, presentes non en todos os lugares da costa, senón alí onde a dinámica mariña destruíu potentes depósitos ou a mesma rocha. E asociado aos ríos aparecen os coios, as coiñeiras, que non están presentes naqueles lugares onde o que abundan son rochas arxilosas. Aquí, pola contra, será normal atopar nomes como lama, lamas, lamoso, etc. Asociados ás canles de auga que discorren por riba de rochas compactas aparecen as fervenzas, os cadoiros, os cachóns, abanqueiro ou freixa que posiblemente non estean presentes nas comarcas onde os ríos discorren por riba de áreas achairadas.

\section{A VARIABILIDADE CLIMÁTICA}

A configuración do relevo xera importantes diferenzas climáticas no noso territorio. Por iso temos sectores, como a Serra do Candán, nos que se poden chegar a recoller máis de $3.000 \mathrm{~mm}$ de auga anual e incluso en anos moi chuviosos máis de $4.000 \mathrm{~mm}$ de auga, caso da estación de Fornelos, por vía de exemplo. Porén, existen outros, como o val do Sil, onde as cifras se sitúan entre os 500 e os $600 \mathrm{~mm}$, caso da estación de Pumares, por vía de exemplo.

O clima galego non se pode explicar sen ter presente a configuración do relevo, tanto como elemento altitudinal como de situación ou orientación. O emprazamento das diferentes unidades, formando unha barreira que illa a costa do interior, así como a ampla gama de bloques a diferente altitude ou a configuración da liña de costa, xeran fortes contrastes entre as distintas comarcas. Isto explica que nas vertentes occidentais da Serra do Candán se recolla a cantidade xa citada e, pola contra, nas terras do Ribeiro, situadas máis ao leste, unicamente se aca- 
den os $800 \mathrm{~mm}$ de media ou no val do Sil aínda máis ao leste, os $600 \mathrm{~mm}$. A finais do verán a configuración do relevo do interior favorece un intenso requecemento, coa conseguinte formación de nubes de desenvolvemento vertical e o desencadeamento de tronadas que, con moita frecuencia, teñen unha incidencia moi negativa sobre os viñedos das comarcas ourensáns do Ribeiro ou Valdeorras.

Pola contra, durante o inverno, a instalación dun potente anticiclón centrado no interior do continente europeo propicia o intenso arrefriamento de boa parte de Galicia, de xeito especial da Galicia interior, e isto favorece a existencia de temperaturas moi baixas, fortes xeadas e inversións térmicas en moitos fondos dos vales, que serran as típicas paisaxes dos mares de nubes.

Asociado ao clima aparecen nomes como néboa, neboeira, brétema, saraiba, orballo..., que teñen igualmente unha desigual repartición en Galicia.

\section{A DIVERSIDADE BIOXEOGRÁFICA}

Os contrastes morfolóxicos, climáticos e edáficos motivan a existencia de marcadas diferenzas bioxeográficas. A nivel xeral, sen ter en conta as transformacións debidas á actividade humana, en Galicia ollamos como o Quercus robur, o carballo, é a especie característica das rexións costeiras mentres que o Quercus pyrenaica, o rebolo, éo das áreas máis secas do sueste, ou o Quercus suber, a sobreira, ben adaptado ás temperaturas extremas e á sequidade, é relativamente frecuente nos vales do Miño e do Sil, mentres que o Quercus petrea, a carba, domina nas montañas de Ancares ou o Betula alba, o bidueiro ou bido, domina en zonas de montaña ou na Terra Chá.

É evidente, pois, que a diferenciación climática se materializa en contrastes termo-pluviométricos e que estes están en íntima relación, non so coa situación de Galicia nas latitudes medias senón, sobre de todo, coa configuración do seu relevo. E este e a súa configuración explican cambios locais que rachan coa tónica xeral. Así as extensas turbeiras do Xistral non se poden explicar unicamente por razóns macroclimáticas, é necesario ponderar o factor microclimático e a topografía. As situadas nos fondos dos vales téñense visto favorecidas 
polas dificultades de avenamento, mentres que as de cobertor, que cobren as partes culminantes dos montes do Xistral e Cuadramón, son froito da choiva oculta, por mor da persistencia de néboas ao longo do ano, froito do feito de que o macizo do Xistral, situado a escasos quilómetros en liña recta do mar Cantábrico, frea a penetración das masas de aire e favorece a súa xénese, o que, á súa vez, propicia a acumulación orgánica.

Ben por razóns climáticas, ben pola actividade humana, o certo é que existen marcadas diferenzas desde o punto de vista da vexetación entre as diferentes comarcas. De novo non en todos os lugares van aparecer as mesmas palabras, pois o medio condiciona a realidade vexetal que marca a existencia dunhas ou outras. Así as fragas abundan na costa, mentres que as devesas son propias do Courel. Piornal ou piornedo non poderiamos atopalos fóra daqueles lugares onde a altitude permite a existencia do piorno. Os toxos, toxeiras e semellantes son nomes propios máis da costa que do interior, mentres que as queirugas, queiroas, queirugal, uces, uceiras... o son do interior, o mesmo que as xestas ou as xesteiras. Teixidal, teixeira, teixido están asociados á presenza desta árbore. Pola contra, ameneiros e salgueiros abundan por toda Galicia, o que facilitará que atopemos nomes asociados a elas por moitos lugares ao igual que freixo ou freixeiro. O érbedo e os nomes a el asociado só aparecerá en lugares moi concretos, dun xeito especial nos vales do sur, o mesmo que as aciñas ou aciñeiras, as azaias, as xaras ou carpazas, propias do ambiente mediterráneo.

\section{VARIABLES FÍSICAS E ACTIVIDADE HUMANA}

É evidente que os contrastes existentes dentro de Galicia son froito dunha complexa dinámica multicausal na que a acción humana foi fundamental. Ata os anos sesenta do século pasado, a ocupación do espazo estivo moi condicionada pola súa potencialidade agronómica. Así, en moitos lugares a aldea asentábase a media ladeira, onde a profundidade do solo non era grande, aproveitando, incluso, algún saínte rochoso, nun lugar orientado ao sur, afastado do fondo do val, onde a falta de insolación e as persistentes néboas invernais, froito das inversións térmicas, creaban un ambiente húmido. Por debaixo, a 
medida que aumentaba a profundidade do solo e preto das vivendas estaban os eidos de cultivo; por riba aparecían os campos de centeo, as faceiras, alí onde a profundidade do solo era menor. Na parte inferior das abas aparecían os lameiros, nun lugar marcado por unha maior profundidade do solo mais tamén por unha maior humidade. Na parte superior aparecía o monte baixo e arredor da aldea permanecían algúns anacos de bosque.

A potencialidade do solo condicionaba o seu uso; os eidos dedicados ao centeo, por exemplo, eran máis abundantes nos solos acedos e secos. O centeo adáptase mellor que o trigo aos solos acedos e, por outra banda, é capaz de medrar aínda naqueles pouco profundos a custa, iso si, de que se cultive seguindo o sistema de barbeito. Pola contra, os máis profundos e, en ocasións, con maior acumulación orgánica, froito da acumulación na base das abas, dedicábanse a prado, dado que o exceso de auga convertíaos en lugares pouco aptos para o cultivo. Noutros lugares as altas temperaturas no verán favoreceron a existencia de viñedos, o que motivou a presenza dun territorio ben diferente. En moitos lugares para cultivar as vides houbo que construír socalcos ou pataus. Para iso foi necesario rachar o monte, achegarlle estrume, gabear con moita frecuencia para que os solos puideran seguir alimentando as plantas. Noutros lugares na economía xogaba un papel moi importante o pastoreo asociado á existencia de pastos en altitude.

$¿$ Que explica todo o anterior? Que os diferentes usos do territorio, as diferentes actividades agrarias e gandeiras tiveron que dar orixe a vocabularios ben diferenciados. Todo o relacionado co viño na comarca do Ribeiro, por vía de exemplo, deu orixe a un propio. As cepas había que gabialas, meterlles esterco ou estrume; había que podalas, facer a rodriga, atalas... Na vendima había que empregar gueipas para recoller os acios e os vagos que caían. Había que levar os culeiros á costa coa axuda da trouxa. Era necesario empregar a muxega para pisalo viño... Nas Serra de Queixa, asociado o pastoreo, aparecen os curros, lugar onde gardar o rabaño, composto de rexelos, durante a noite. O rabaño medíase por días e non por cabezas. Iso vén de que cada veciño debía ir co pastor ou só ao monte coidar os rexelos en función dun determinado número deles; ás veces dez, ás veces doce. Iso deu lugar á ronda ou a veceira.

Quero dicir con todo o anterior que rexelo ou veceira dificilmente o escoitaremos no Salnés. Porén, tampouco escoitaremos falar de con na 
Serra de Queixa. Que, en función da explotación da terra, do uso do territorio, da súa configuración xeográfica, entendendo por iso aspectos morfolóxicos, estruturais, litolóxicos, climáticos ou bioxeográficos, teremos unha ou outras palabras. Agros e agras, leiras ou eidos, lameiros ou prados, centeeiras ou naveiras; quenllas ou sendeiros, cabanas ou pallozas, cabazos ou hórreos ou cabaceiros, molidas ou trouxas, tapadas ou campas... amosan a enorme riqueza lingüística relacionada coas actividades económicas dos labregos.

\section{CONCLUSIÓNS}

Ao longo das liñas anteriores coido que quedou clara unha cousa: a importancia dos elementos xeográficos na construción da linguaxe; o papel das variables físicas ou humanas nas variacións que podemos atopar.

É por iso polo que eu animaría os novos investigadores a non só levar a cabo unha recollida a fondo da toponimia ou da fala, senón tamén a tentar relacionar os diferentes nomes coas características xeográficas dos lugares. Posiblemente se poderían comprender mellor as diferenzas existentes. E, asemade, lanzo a idea que xa repetín moitas veces ao longo dos anos: ¿por que non facermos un dicionario de termos xeográficos galegos? Non en galego, senón galego. Iso permitiría recoller e agrupar a enorme riqueza de termos existente no noso territorio. 
ANEXO

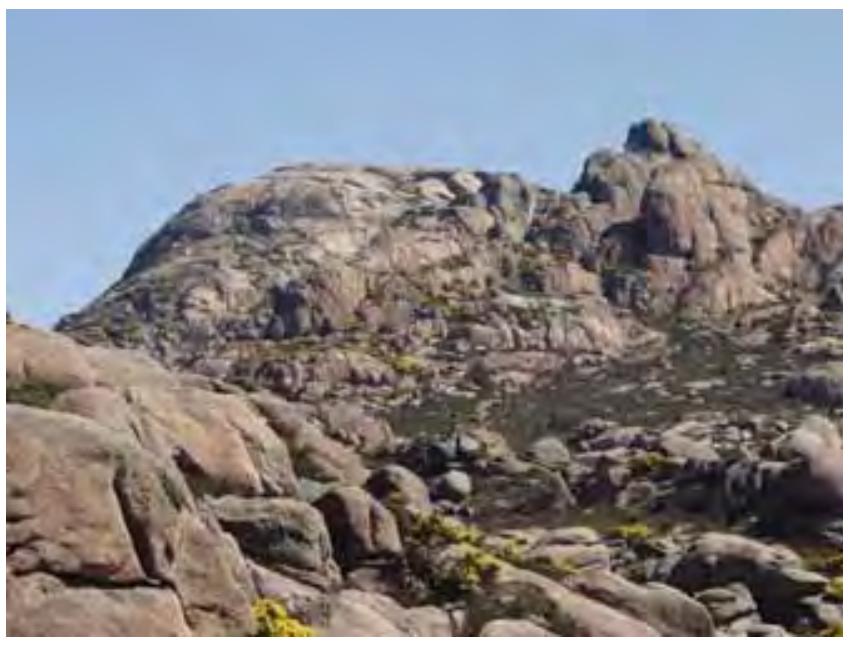

Figura 1. Nas áreas graníticas aparecen formas ben diferenciadas que levan nomes singulares, como o caso de moa. O Pindo (A Coruña).

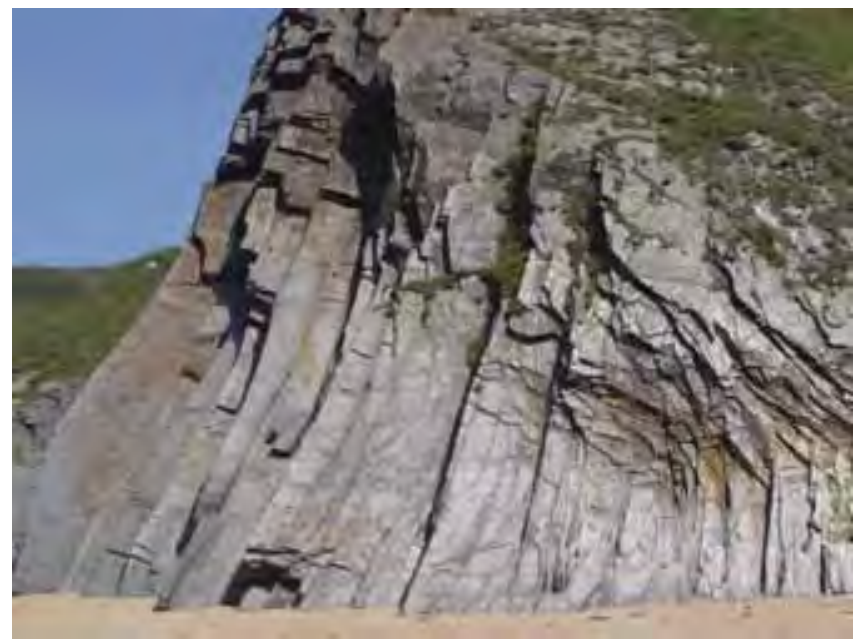

Figura 2. As rochas metamórficas non só presentan características morfolóxicas diferentes, senón que levan asociados topónimos ben diferentes das rochas graníticas. Praia do Picón (Ortigueira, A Coruña). 


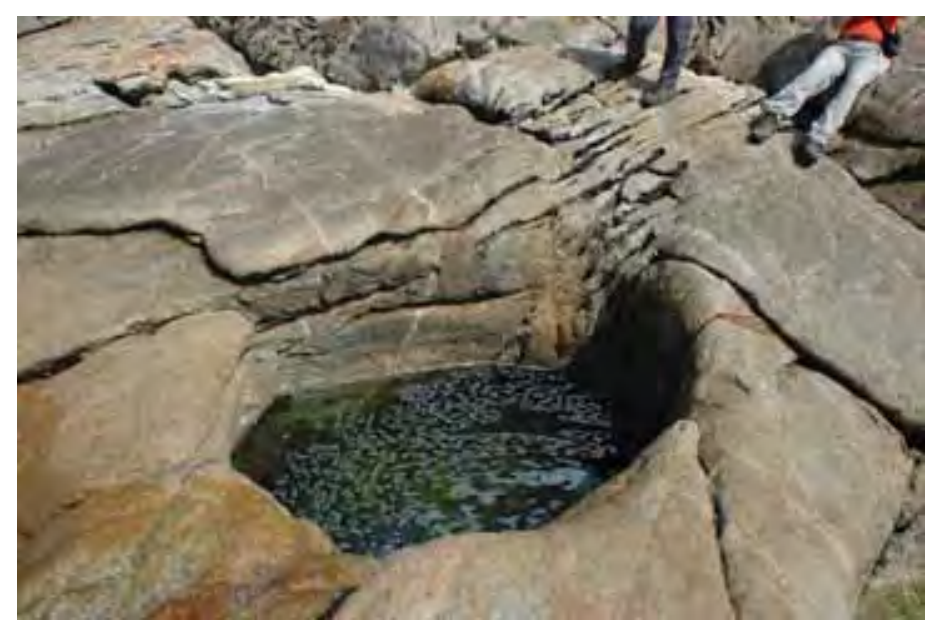

Figura 3. Os procesos derivados da dinámica xeomorfolóxica xeran, tanto na costa coma no interior, microformas coma as pías. Oia (Pontevedra).

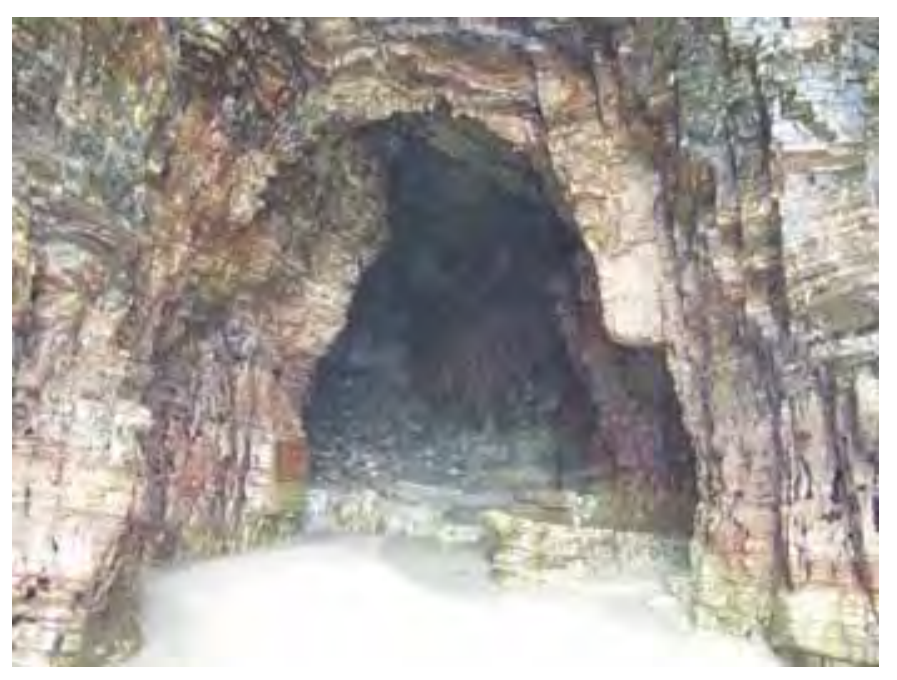

Figura 4. As furnas son elementos singulares da costa de Galicia. Praia de Augasantas (A Devesa, Ribadeo). 


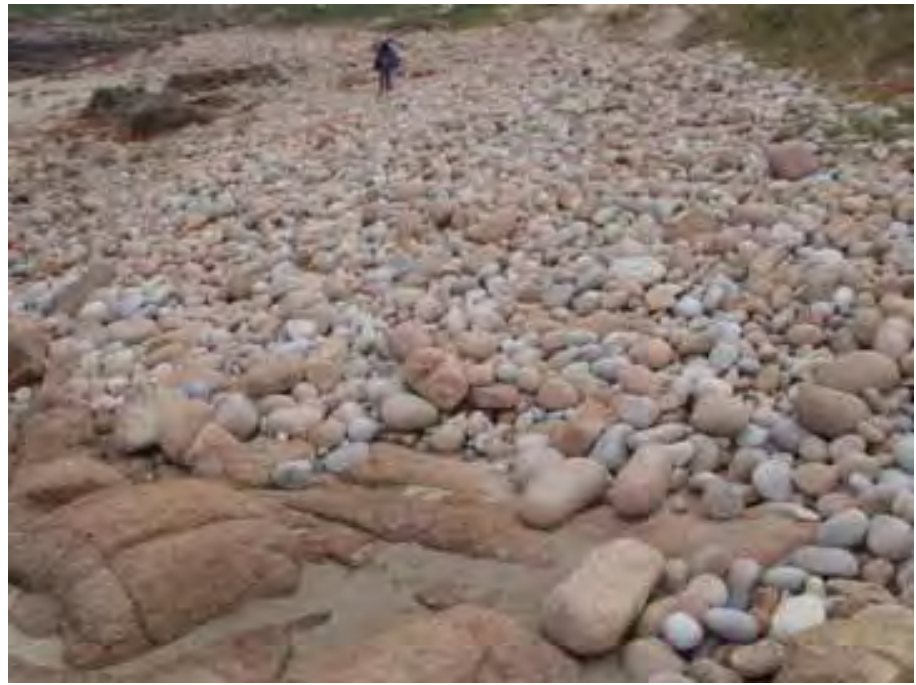

Figura 5. Os coídos non só son acumulacións de blocos. Xeran unha terminoloxía única no mundo. Praia do Trece (Camariñas, A Coruña).

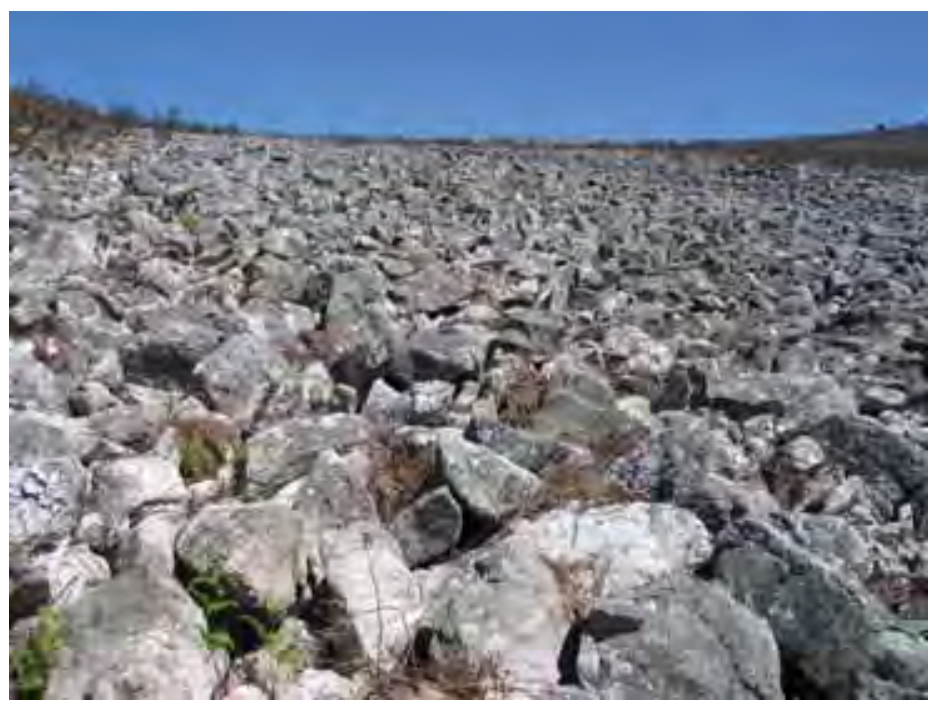

Figura 6. Froito da dinámica periglaciar, por mor de procesos de xeo/desxeo, xurdiron os pedregais. Pedregal de Irimia (Meira, Lugo). 


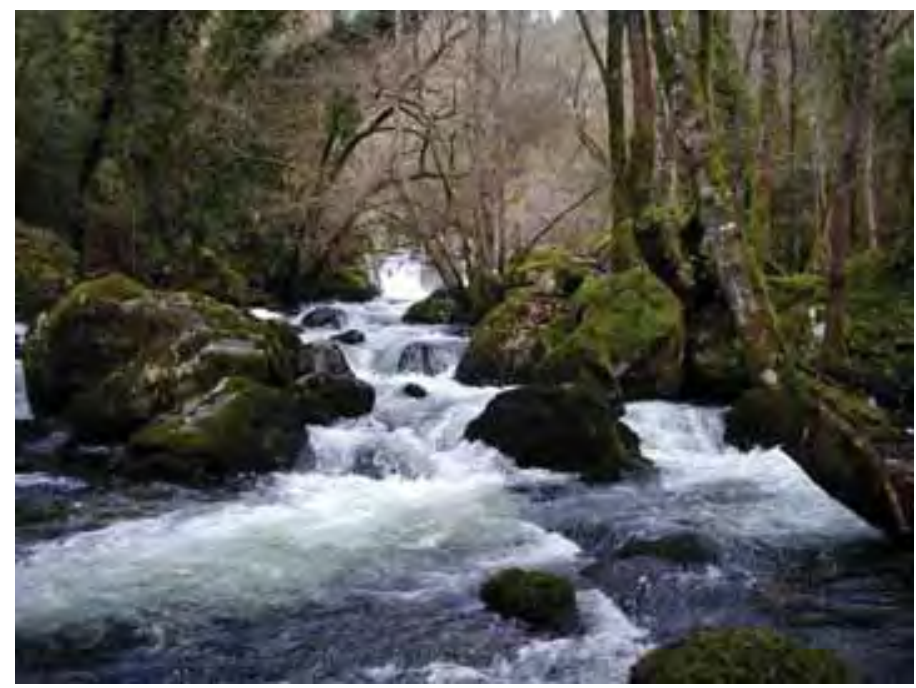

Figura 7. Os cachóns son característicos de ríos co leito rochoso. Río Arenteiro (O Carballiño, Ourense).

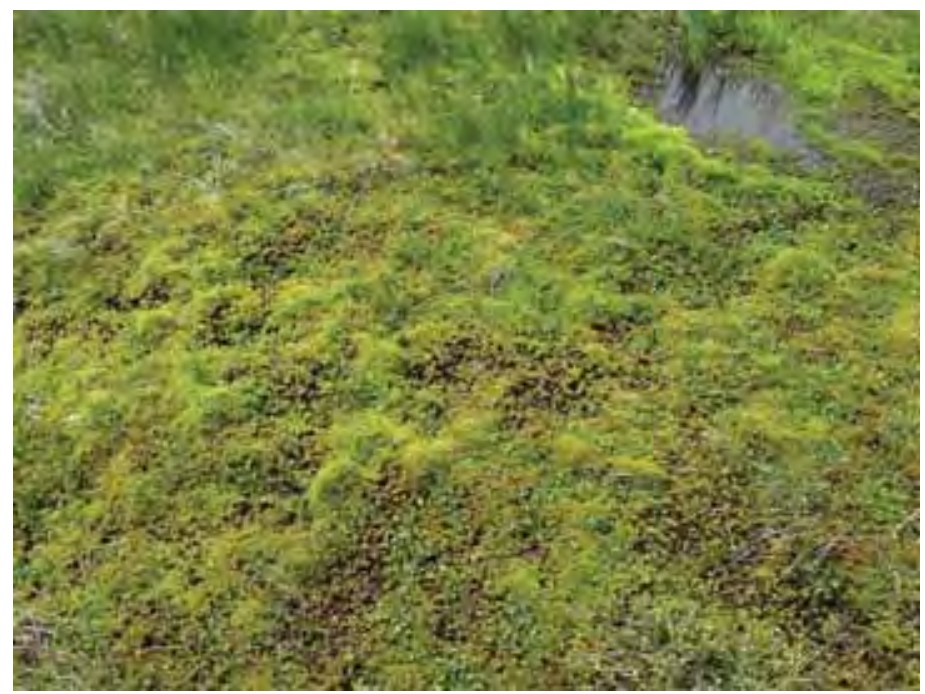

Figura 8. Asociadas á presenza de auga están as brañas e as turbeiras. Turbeira do Xistral (Lugo). 


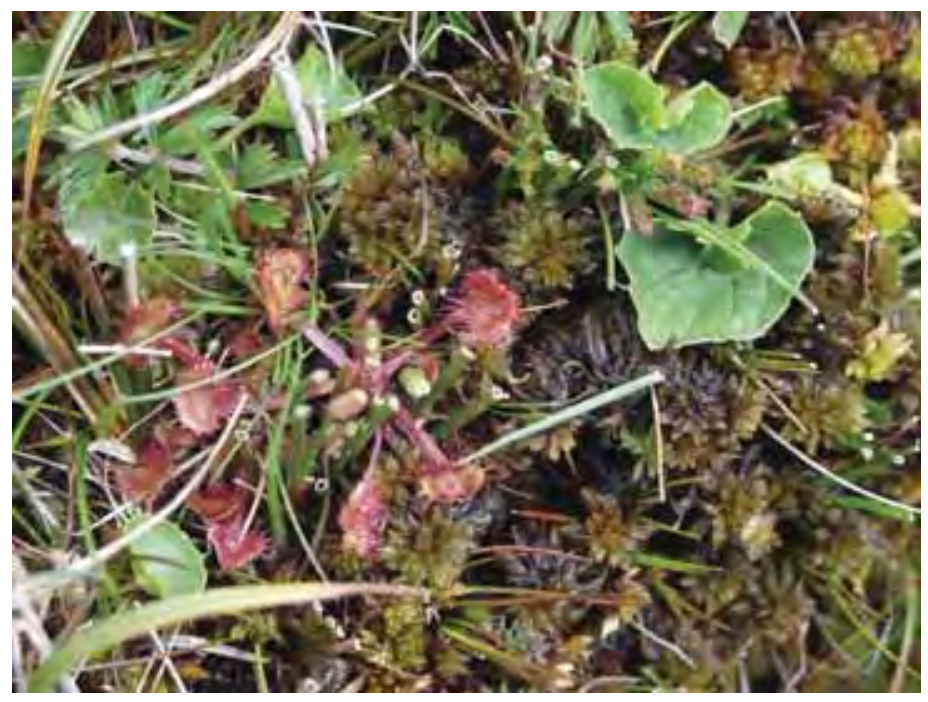

Figura 9. A flora é unha boa indicadora das condicións climáticas ou, coma neste caso, das hidromorfas. Unha planta característica das turbeiras é a drosera.

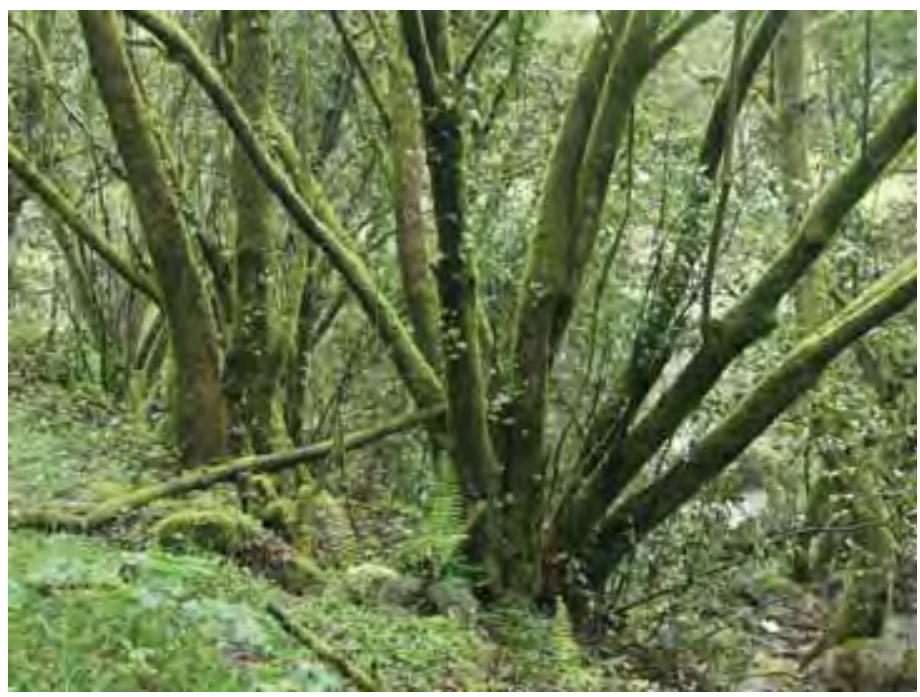

Figura 10. Asociadas á auga aparecen especies coma os ameneiros ou os salgueiros. Río Deza (Carboeiro, Pontevedra). 


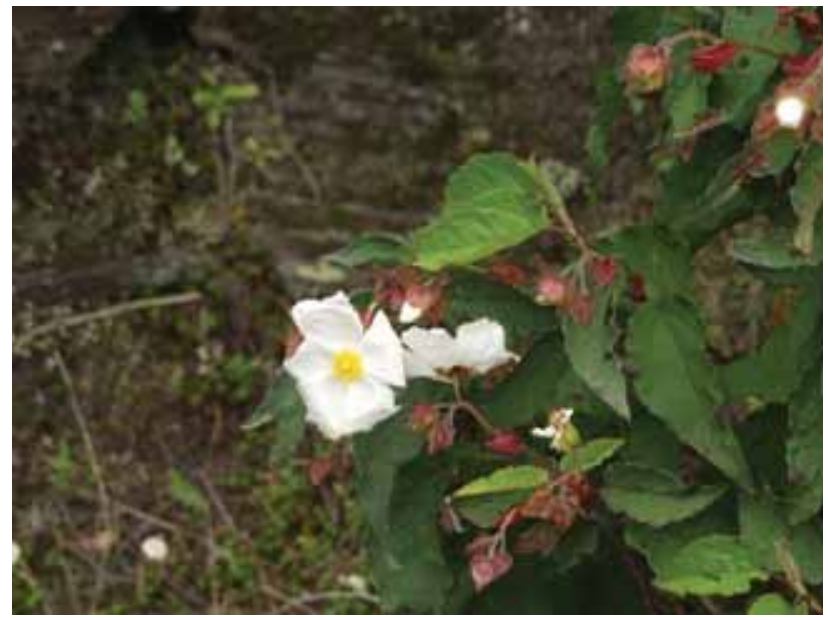

Figura 11. Certas prantas e, xa que logo, certos nomes son propios da rexión mediterránea, coma o caso das xaras. Val do Sil (Ourense).

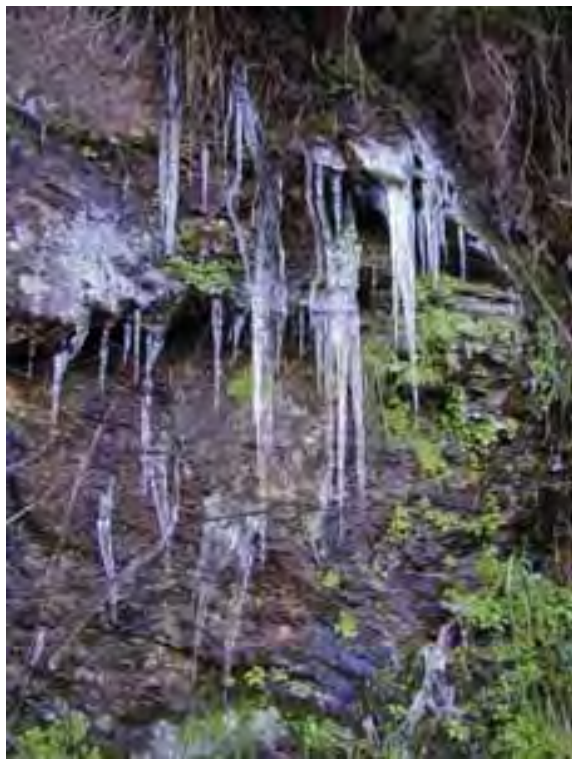

Figura 12. As variables climáticas xeran no só condicións concretas nas diferentes rexións de Galicia, senón nomes asociados a elas. Carambelos en Leiro (Ourense). 


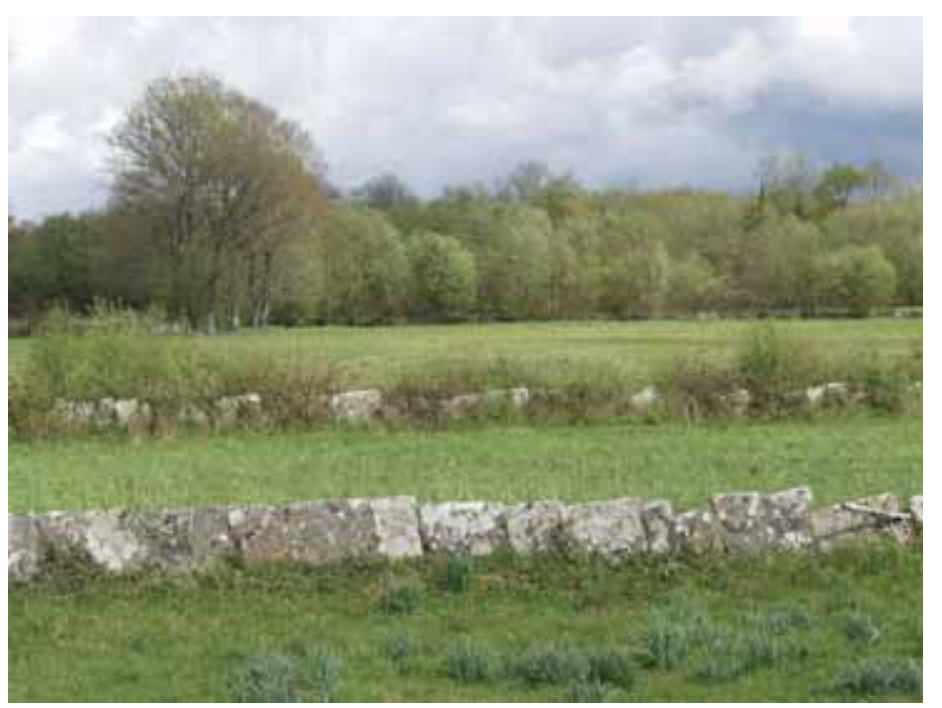

Figura 13. A rocha non só inflúe no modelado do relevo, tamén condiciona o uso do chan. Chantos ou bargos na Terra Cha (Lugo).

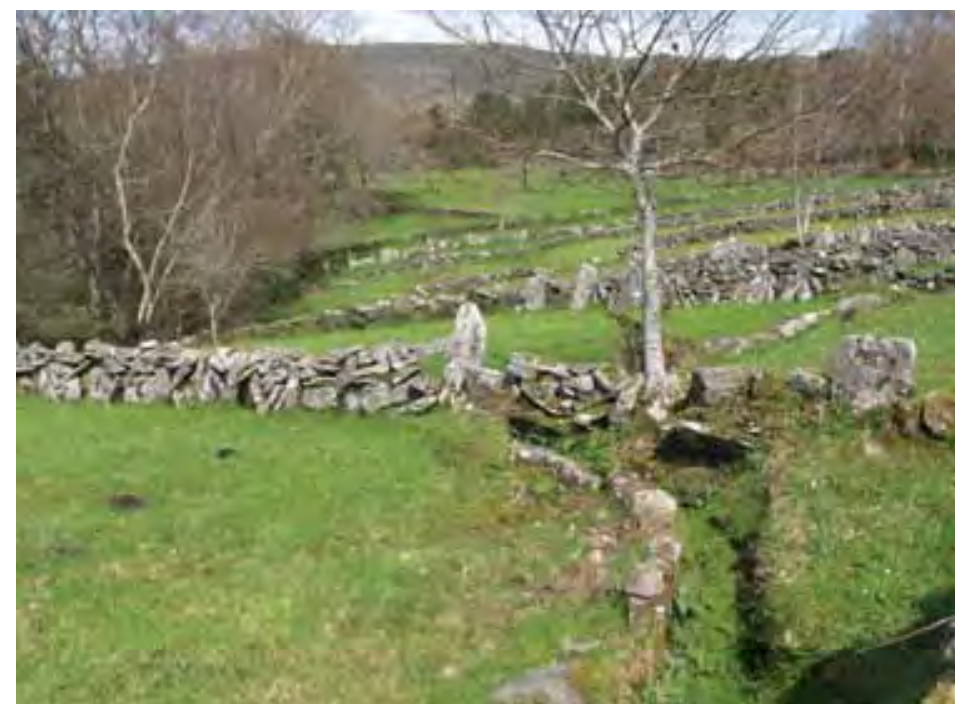

Figura 14. A paisaxe que aparece na imaxe é ben diferente da anterior. Trátase de muros de pedra de gra en Oseira (Ourense). 


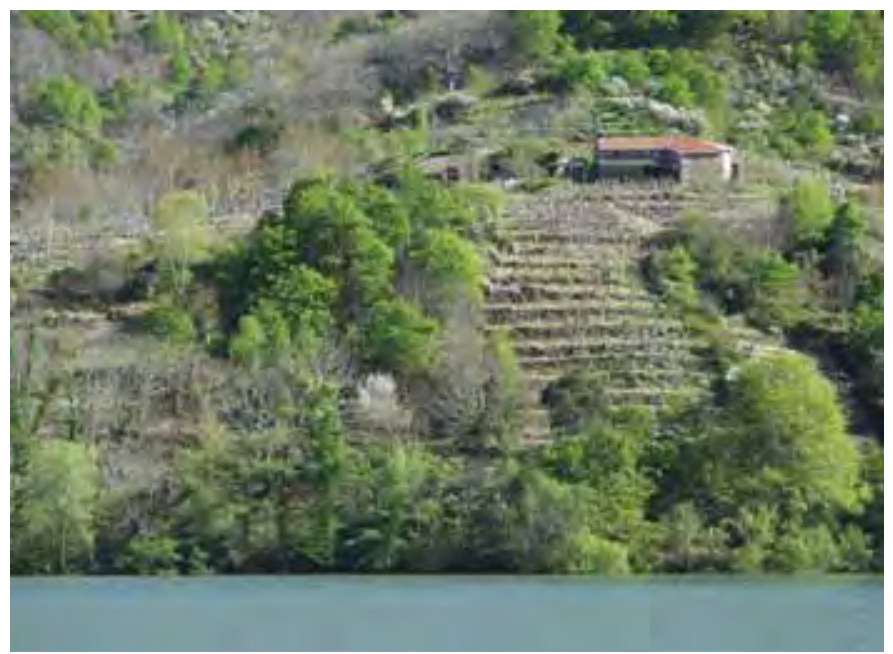

Figura 15. A reestruturación do territorio xerou non só cambios na paisaxe, senón a presenza de nomes coma socalcos existentes en lugares concretos de Galicia. Val do Sil (Lugo). 